\title{
Glomerular filtration rate in patients with Cushing's disease: a matched case-control study
}

\author{
P Haentjens, L De Meirleir, R Abs ${ }^{1}$, J Verhelst ${ }^{2}$, K Poppe and B Velkeniers \\ Department of Endocrinology, Academisch Ziekenhuis van de Vrije Universiteit Brussel (AZ-VUB), Laarbeeklaan 101, B-1090 Brussels, Belgium, \\ ${ }^{1}$ Universitair Ziekenhuis, B-2650 Antwerpen, Belgium and ${ }^{2}$ Middelheim Ziekenhuis, B-2020 Antwerpen, Belgium \\ (Correspondence should be addressed to B Velkeniers; Email: brigitte.velkeniers@az.vub.ac.be)
}

\begin{abstract}
Background: Patients with Cushing's disease have a high prevalence of atherosclerosis and maintain an increased cardiovascular risk even after cure of the disease. However, the impact of Cushing's disease on renal function remains to be quantified.

Objectives: To evaluate glomerular filtration rate (GFR) and to identify predictors of GFR in patients with Cushing's disease.

Design and methods: We conducted a matched case-control study: 18 patients with active or cured Cushing's disease were compared with healthy population controls matched for age and sex. The main outcome measures were GFR and micro-albuminuria.

Results: Patients with Cushing's disease had a lower GFR, as measured by 24-h creatinine clearance (79 versus $95 \mathrm{ml} / \mathrm{min}$ per $1.73 \mathrm{~m}^{2}, P=0.005$ ) and estimated by the $\mathrm{MDRD}_{2}$ formula (75 versus $88 \mathrm{ml} / \mathrm{min}$ per $1.73 \mathrm{~m}^{2}, P=0.008$ ). Multiple regression analyses indicated that disease duration was the strongest predictor for a worse GFR. The prevalence of micro-albuminuria was low (5.5\% in both groups).

Conclusions: Patients with Cushing's disease have a decreased GFR. Even if they are cured, close follow-up with strict control of cardiovascular risk factors and monitoring of GFR seems mandatory. Furthermore, the dosage of certain drugs should be adapted to the individual GFR.
\end{abstract}

European Journal of Endocrinology 153 819-829

\section{Introduction}

Cushing's disease, a rather rare disease with an incidence of about 2.4 per million people per year, affects women 5 to 8 times more frequently than men, and its peak incidence occurs between ages 25 and 40 years $(1-3)$.

Patients with Cushing's disease have an increased risk for developing cardiovascular disease. Chronic hypercortisolemia is associated with cardiovascular risk factors such as systemic arterial hypertension, impaired glucose tolerance or diabetes mellitus, central obesity with insulin resistance, hyperlipidemia and hypercoagulability. The increased cardiovascular risk can persist a long time after remission of the disease. In this regard, Colao et al. (4) reported that patients with a history of Cushing's disease have a high prevalence of atherosclerosis and keep an increased cardiovascular risk even after normalization of circulating cortisol levels for 5 years or more. The same authors provide evidence for the fact that abdominal obesity and/or insulin resistance are the most important factors contributing to this cardiovascular risk (4).

Cardiovascular risk factors also have a major impact on renal function (5). More specifically, the metabolic syndrome, of which many features are present in Cushing's disease, is a strong and independent risk factor for chronic kidney disease and micro-albuminuria (6).

It is somewhat surprising therefore, that data on renal function in patients with Cushing's disease are scarce $(7-10)$. So far, no studies have examined the potential effect of cardiovascular risk factors on renal function in these patients. If renal function is impaired, and if the factors contributing to renal impairment are identified, this could have therapeutic implications in terms of prevention of renal dysfunction.

We therefore performed a matched case-control study with a 2-fold aim: first, to investigate if patients with Cushing's disease have a decreased glomerular filtration rate (GFR) in comparison to the normal population; secondly, to explore the potential impact of different factors known to be present in glucocorticoid excess on GFR.

\section{Patients and methods}

\section{Overall study design and patient recruitment}

The design was a matched case-control study. Patients previously diagnosed with Cushing's disease (cases) were matched, with respect to age ( \pm 3 years) 
and sex, with healthy subjects from the general population (controls). All subjects gave written informed consent. Criteria for exclusion from the study were a familial or personal history of kidney disease before the onset of the Cushing's disease. The protocol and consent form were approved by the Ethical Committee of the Vrije Universiteit Brussel (Brussels, Belgium).

Patients with Cushing's disease were recruited from three hospitals (Academisch Ziekenhuis van de Vrije Universiteit Brussel, Universitair Ziekenhuis Antwerpen, and Middelheim Ziekenhuis Antwerpen) between March and December 2003. The diagnosis of Cushing's disease, made between 1982 and 2003, was based on: (i) increased diurnal urinary cortisol excretion; (ii) increased basal serum cortisol levels with loss of physiological circadian rhythm with normal or increased plasma adrenocorticotropic hormone (ACTH) concentrations; (iii) lack of cortisol suppression after administration of low-dose dexamethasone. In all patients, the presence of a pituitary tumor was confirmed by computed tomography or magnetic resonance imaging (MRI) and/or inferior petrosal sinus sampling.

The criteria considered for cure of Cushing's disease were defined by: (i) urinary diurnal cortisol excretion below or within the normal range; (ii) serum cortisol concentrations below or within the normal range; (iii) suppression of serum cortisol concentrations after $1 \mathrm{mg}$ dexamethasone (11).

The following data were extracted from patient files: age at diagnosis, gender, duration of active disease, clinical features at diagnosis (including appearance of weight increase, central fat distribution, moonface, buffalo hump, purple striae, ecchymosis, thinning of the skin, myopathy, edema, hirsutism, acne, menstrual disorders, headache, blurred vision, psychiatric disorders, hypertension, diabetes mellitus and/or impaired glucose tolerance, pituitary deficiency, osteoporosis, and presence of nephrolithiasis), 24-h cortisoluria and plasma ACTH and cortisol levels at diagnosis, results of imaging studies, outcome of surgery, additional radiation therapy, surgery and/or specific medication.

We also documented the current status of Cushing's disease (cured or active), smoking status and the current use of medication.

\section{Clinical and biochemical measurements}

Current height, weight, body mass index (BMI), waist and measurements of heart rate, systolic blood pressure, and diastolic blood pressure were evaluated by standard methods in both groups, i.e. among cases (patients who have suffered or have Cushing's disease) and controls (healthy persons from the general population). Overweight was defined as a BMI of
$25-29.9 \mathrm{~kg} / \mathrm{m}^{2}$ and obesity as a BMI $\geqq 30 \mathrm{~kg} / \mathrm{m}^{2}$ (12). Blood pressure was measured in a relaxed sitting position with a mercury sphygmomanometer. Hypertension was diagnosed when systolic blood pressure was more than $140 \mathrm{mmHg}$ and/or diastolic blood pressure was more than $90 \mathrm{mmHg}$ (13).

Creatinine clearance was computed from creatinine excretion in a 24-h urine collection and a single measurement of serum creatinine. Plasma and urine creatinine were measured in the same laboratory by using the Vitros enzymatic creatinine assay (Ortho-Clinical Diagnostics, Inc., 100 Indigo Creek Drive, Rochester, NY, USA) with a normal range in plasma of $0.5-1.5 \mathrm{mg} / \mathrm{dl}$ in adult men and $0.4-$ $1.2 \mathrm{mg} / \mathrm{dl}$ in women. The precision of the assay was characterized by a coefficient of variation of $1.7 \%$ at $0.87 \mathrm{mg} / \mathrm{dl}$ and $1.3 \%$ at $5.95 \mathrm{mg} / \mathrm{dl}$ during the study. The accuracy of the assay was characterized by a coefficient of variation of $8.7 \%$ at $0.85 \mathrm{mg} / \mathrm{dl}, 0.9 \%$ at $0.90 \mathrm{mg} / \mathrm{dl}, 2.9 \%$ at $0.99 \mathrm{mg} / \mathrm{dl}, 3.4 \%$ at $1.96 \mathrm{mg} / \mathrm{dl}$, $1.5 \%$ at $2.00 \mathrm{mg} / \mathrm{dl}$ and $3.7 \%$ at $6.30 \mathrm{mg} / \mathrm{dl}$. The $z-$ scores for accuracy, ranging between -0.69 and 1.19, provided no evidence for a statistically significant over- or underestimation of plasma creatinine measurements compared with the external reference standard of the Federal Government (Federale Overheisdsdienst Volksgezondheid, Veiligheid van de Voedselketen en Leefmilieu, Externe Kwaliteitsevaluatie, Juliette Wytsmanstraat 14, Brussels; http://www.iph. fgov.be). The assay had very stable quality control measures during the duration of the study (betweenday imprecision of less than $2.5 \%$ at levels of 0.65 and $7.59 \mathrm{mg} / \mathrm{dl}$, Laboratory Procedures Manual 2003, Academisch Ziekenhuis van de Vrije Universiteit Brussel).

The serum and urine specimens were also used for other measurements. Plasma renin, aldosterone, insulin, ACTH and serum and urinary cortisol were assayed by immunoradiometric assay (IRMA) or by radioimmunoassay. Plasma urea, total cholesterol, lowdensity lipoprotein (LDL)-cholesterol, high-density lipoprotein (HDL)-cholesterol, triglycerides, hemoglobin, hematocrit, red blood cells, glucose, hemoglobin A1c and electrolytes were measured by standard laboratory procedures. Calciuria and urinary creatinine were quantified on a 24-h urine collection. Completeness of urinary collection was determined by creatinine excretion over $24 \mathrm{~h}$.

Urinary micro-albumin was measured on a 24-h urine collection, using an immuno-turbidimetric method (Roche-Diagnostics), and was considered positive if it exceeded $30 \mathrm{mg} / 24 \mathrm{~h}$

\section{Assessment of GFR (primary outcome measure)}

In both groups GFR was evaluated by several noninvasive methods. 
Twenty-four-hour creatinine clearance was calculated using the following formula:

$$
\begin{aligned}
\text { Creatinine clearance }= & \operatorname{urinary} \text { creatinine }(\mathrm{mg} / \mathrm{dl}) \\
& \times 24-\mathrm{h} \text { urinary volume }(\mathrm{ml} / \mathrm{min}) / \\
& \text { serum creatinine }(\mathrm{mg} / \mathrm{dl})
\end{aligned}
$$

We also normalized the 24-h creatinine clearance for a body surface of $1.73 \mathrm{~m}^{2}$, using the Mosteller formula for body surface area (14):

$$
\begin{aligned}
\text { Body surface area }\left(\mathrm{m}^{2}\right)= & {[\text { height }(\mathrm{cm}) \times \text { weight }(\mathrm{kg}) /} \\
& 3600] \exp 1 / 2
\end{aligned}
$$

The Cockcroft-Gault formula was also used to estimate GFR:

$$
\begin{aligned}
\operatorname{GFR}(\mathrm{ml} / \mathrm{min})= & {[140-\text { age }(\text { years })] \times \text { weight }(\mathrm{kg}) } \\
& \times(0.85 \text { if woman }) /
\end{aligned}
$$$$
\text { [72 } \times \text { plasma creatinine }(\mathrm{mg} / \mathrm{dl})]
$$

Cockcroft-Gault estimates of GFR were also normalized for a body surface of $1.73 \mathrm{~m}^{2}$.

GFR was also estimated by using the simplified Modification of Diet in Renal Disease Study equation $\left(\mathrm{MDRD}_{2}\right)$, defined as follows $(15,16)$ :

$$
\begin{aligned}
& \operatorname{GFR}\left(\mathrm{ml} / \mathrm{min} \text { per } 1.73 \mathrm{~m}^{2}\right) \\
& =186 \times \text { serum creatinine }{ }^{-1.154} \\
& \times \operatorname{age}^{-0.203} \times(0.742 \text { if woman }) \\
& \times(1.210 \text { if Afro-American })
\end{aligned}
$$

\section{Statistical analyses}

Data on demographic characteristics, clinical and biochemical measurements were summarized descriptively for both groups, i.e. patients with Cushing's disease and healthy controls. Differences in the mean values of continuous variables among the matched groups were evaluated by the paired Student's $t$-test for normally distributed variables and Wilcoxon signed ranks test for other variables. No adjustments for multiple comparisons were made to the reported $P$ values. Readers become able therefore, if they so desire, to do a Bonferroni (or other) adjustment for the multiplicity.

Next, a one-way between-groups multivariate analysis of variance (MANOVA) was performed to investigate differences in GFR between the group of patients with Cushing's disease and the control group.

Five dependent variables (primary outcome measures) were used in the MANOVA model: 24-h creatinine clearance, 24-h creatinine clearance normalized for a body surface of $1.73 \mathrm{~m}^{2}$, GFR estimated by the Cockcroft-Gault formula, GFR estimated by the Cockcroft-Gault formula normalized for a body surface of $1.73 \mathrm{~m}^{2}$ and GFR calculated according to the $\mathrm{MDRD}_{2}$ formula. Given the small sample size of our pilot study we performed statistical tests on logtransformed data for the five dependent variables. To facilitate clinical interpretation, the results were re-expressed in terms of the original units.

The independent variable of the MANOVA model was defined by group, i.e. patients with Cushing's disease versus healthy controls.

The significance of the overall MANOVA model was assessed by Wilk's lambda statistic, the $F$ statistic and the corresponding $P$ value. Only a single test is performed to assess whether the five dependent variables (as a cluster) differ among patients with Cushing's disease versus healthy controls. To assess whether each individual outcome measure was statistically different among groups, we chose to regard a level of $P<0.01$ as significant for these individual comparisons, representing a Bonferroni correction of 0.05 divided by the five outcome measures of primary interest.

Finally, we used multiple regression analyses to investigate the joint effect and independent contribution of several factors (explanatory variables) on GFR (dependent variables) among patients with Cushing's disease.

The five primary outcome measures - i.e. GFR measured by a 24-h creatinine clearance and normalized for a body surface of $1.73 \mathrm{~m}^{2}$, GFR estimated by the Cockcroft-Gault formula and normalized for a body surface of $1.73 \mathrm{~m}^{2}$, and GFR calculated using the $\mathrm{MDRD}_{2}$ formula - were modeled separately.

A series of multiple regression analyses were conducted to identify and confirm the combination of variables that was most effective for predicting each outcome measure of primary interest. The following variables were considered for inclusion in the multiple regression models as possible predictors of each outcome variable of interest: gender, duration of active disease, weight increase, smoking status, pituitary deficiency and age at diagnosis; current BMI, waist, heart rate, systolic blood pressure, diastolic blood pressure, total cholesterol, LDL-cholesterol, HDL-cholesterol, triglycerides and glucose levels; current antihypertensive and hyperlipemic drug use. These variables describe patient characteristics at diagnosis considered to be useful to predict or confound renal function, and well-known risk factors for cardiovascular disease. To determine which of these candidate variables might be useful in the multiple regression models, the association between each candidate variable and each outcome measure of interest was assessed separately. Stepwise multiple regression calculations were then performed with candidate variables entered that showed $P$ values $<0.05$ when assessed separately. 
For each multiple regression model the significance of the overall model was assessed by the $F$ statistic. This was because only a single test is performed to assess whether the independent variables (as a group) are associated with the outcome without worrying about adjusting for multiple comparisons. To assess whether the individual independent variables from each multiple regression model were statistically associated with the outcome of interest, the readers become able, if they so desire, to do a Bonferroni (or other) adjustment for the multiplicity. To calculate the Bonferroni correction the usual $P$ value (e.g. 0.05) is simply divided by the number of independent (predictor) variables in the model.

All data analyses were performed using SPSS version 12.0 (SPSS, Inc., Chicago, IL, USA).

\section{Results}

\section{Characteristics of patients with Cushing's disease}

We enrolled 18 patients previously diagnosed with Cushing's disease: 3 patients with active Cushing's disease ( 2 men, 1 woman; mean age 51 years) and 15 patients cured of Cushing's disease ( 3 men, 12 women; mean age 45 years).

The initial diagnosis of Cushing's disease was based on three diagnostic tests in eight patients (a low-dose dexamethasone test, MRI and sinus petrosus sampling), and on two tests in ten patients (low-dose dexamethasone test and MRI). The clinical features of the patients at initial diagnosis are shown in Table 1.

All 18 patients had undergone transsphenoidal pituitary adenomectomy one or more times. In 12 patients this was unsuccessful, and additional therapy was needed. Additional therapy included pituitary irradiation

Table 1 Clinical characteristics of patients with Cushing's disease at diagnosis.

\begin{tabular}{lr}
\hline Clinical feature & Number (\%) \\
\hline Weight increase & $16 / 18(89 \%)$ \\
Central fat distribution & $11 / 18(61 \%)$ \\
Moonface/buffalo hump & $12 / 18(67 \%)$ \\
Thin skin with easy bruising & $6 / 18(33 \%)$ \\
Striae & $6 / 18(33 \%)$ \\
Myopathy & $6 / 18(33 \%)$ \\
Edema & $6 / 18(33 \%)$ \\
Hirsutism* & $10 / 13(77 \%)$ \\
Menstrual disorders* & $8 / 13(61 \%)$ \\
Headache/blurred vision & $9 / 18(50 \%)$ \\
Psychiatric disorders & $5 / 18(28 \%)$ \\
Hypertension & $9 / 18(50 \%)$ \\
Diabetes mellitus/glucose intolerance & $2 / 18(11 \%)$ \\
Osteoporosis & $3 / 18(17 \%)$ \\
Nephrolithiasis & $3 / 18(17 \%)$ \\
\hline
\end{tabular}

*Applicable to women only. (stereotactic and classical) and chemical or surgical adrenalectomy.

Upon entry in the current case-control study, 15 out of 18 patients with Cushing's disease were declared cured; of these 15 patients, the 8 patients who had developed hypocorticism were treated by corticosteroid substitution (hydrocortisone, 20-30 mg daily). Three patients suffered from active Cushing's disease: 1 patient had hypercortisolemia, and 2 patients showed normal cortisol levels under treatment. At study entry, secondary hypopituitarism was observed in 13 patients. All patients with secondary pituitary deficiencies were treated with hormonal replacement at the appropriate doses. Other clinical features of the patients with Cushing's disease upon entry in the current case-control study were: arterial hypertension in 5 patients ( 1 patient was treated by an angiotensin-converting enzyme (ACE)-inhibitor, the other patients received other antihypertensive drugs), diabetes mellitus in 1 patient, and medication for dyslipidemia in 5 patients. Three patients were smokers. Seven patients were overweight and 2 patients were obese (compared with 5 overweight people in the control group).

\section{Clinical and biochemical data: patients with Cushing's disease versus controls}

Table 2 shows the current characteristics of the patients with Cushing's disease (cases) and the matched healthy individuals (controls) upon entry in our case-control study. In the group with Cushing's disease, height was significantly lower $(P=0.003)$ than in the controls. Weight, BMI, waist, blood pressure and heart rate at rest were not significantly different between the two groups.

Patients with Cushing's disease had significantly higher plasma creatinine $(P=0.017)$ and plasma urea $(P=0.014)$ levels, and significantly lower 24-h calciuria $(P=0.002)$, hematocrit $(P=0.022)$, total red blood cells $(P=0.017)$ and glucose $(P=0.026)$ levels than the controls. Blood lipid levels, hormonal levels (renin, aldosterone, insulin, ACTH, serum cortisol and cortisoluria), hemoglobin A1c and serum electrolytes were not significantly different between the two groups.

Micro-albuminuria was present in one patient with Cushing's disease, and in one patient from the control group (5.5\% in both groups).

When the group of patients with Cushing's disease was stratified according to corticosteroid substitution therapy, the eight patients taking hydrocortisone were older (53 versus 42 years, $P=0.038$ ), had lower plasma cortisol (66 versus $227 \mu \mathrm{g} / \mathrm{l}, P=0.002$ ) and higher plasma urea levels $(50$ versus $31 \mathrm{mg} / \mathrm{l}$, $P=0.013)$. 
Table 2 Current clinical and biochemical characteristics of 18 patients with Cushing's disease and 18 healthy population controls.*

\begin{tabular}{|c|c|c|c|}
\hline & $\begin{array}{c}\text { Cushing's disease } \\
\text { (cases) }\end{array}$ & $\begin{array}{l}\text { Healthy individuals } \\
\text { (controls) }\end{array}$ & $P$ value \\
\hline Age (years) & $47(12)$ & $47(12)$ & 1.000 \\
\hline Height $(\mathrm{cm})$ & $163(7)$ & $169(8)$ & 0.003 \\
\hline Weight (kg) & $73(19)$ & $72(14)$ & 0.903 \\
\hline Body surface $\left(\mathrm{m}^{2}\right)$ & $1.80(0.22)$ & $1.83(0.20)$ & 0.642 \\
\hline $\mathrm{BMI}\left(\mathrm{kg} / \mathrm{m}^{2}\right)$ & $27.7(8.1)$ & $25.2(3.5)$ & 0.273 \\
\hline Waist $(\mathrm{cm})$ & $94(18)$ & $89(12)$ & 0.372 \\
\hline Heart rate (pulses/min) & $76(13)$ & $77(7)$ & 0.767 \\
\hline Systolic blood pressure (mmHg) & $124(15)$ & $123(14)$ & 0.691 \\
\hline Diastolic blood pressure $(\mathrm{mmHg})$ & 79 (8) & $76(8)$ & 0.299 \\
\hline $\operatorname{Renin}(\mathrm{ng} / \mathrm{l})$ & $9.2(5.9)$ & $10.5(5.8)$ & 0.971 \\
\hline Aldosterone (ng/l) & $232(460)$ & $116(58)$ & 0.368 \\
\hline Insulin (mIU/l) & $6.65(2.78)$ & $7.21(5.18)$ & 0.854 \\
\hline ACTH $(n g / l)$ & $94(185)$ & $29(20)$ & 0.162 \\
\hline Serum cortisol $(\mu \mathrm{g} / \mathrm{l})$ & $156(118)$ & $169(77)$ & 0.606 \\
\hline 24-h urinary volume (ml/day) & $1863(666)$ & 2131 (995) & 0.478 \\
\hline 24-h urinary creatinine (g/day) & $1.14(0.21)$ & $1.18(0.25)$ & 0.692 \\
\hline 24-h urinary calcium (mg/24 h) & $118(48)$ & $192(88)$ & 0.002 \\
\hline 24 -h urinary cortisol $(\mu \mathrm{g} / 24 \mathrm{~h})$ & $66(42)$ & $48(17)$ & 0.086 \\
\hline Plasma creatinine $(\mathrm{mg} / \mathrm{dl})$ & $0.98(0.24)$ & $0.84(0.13)$ & 0.017 \\
\hline Plasma urea $(\mathrm{mg} / \mathrm{dl})$ & 39 (17) & $27(5)$ & 0.014 \\
\hline Total cholesterolemia (mg/dl) & $215(38)$ & $215(34)$ & 0.930 \\
\hline HDL-cholesterolemia (mg/dl) & $65(17)$ & $62(17)$ & 0.674 \\
\hline LDL-cholesterolemia (mg/dl) & 127 (33) & $130(29)$ & 0.868 \\
\hline Triglycerides (mg/dl) & $102(44)$ & $116(49)$ & 0.373 \\
\hline Hemoglobin $(\mathrm{g} / \mathrm{dl})$ & $13.8(1.1)$ & $14.3(0.9)$ & 0.143 \\
\hline Hematocrit (\%) & $41.1(3.3)$ & $43.6(2.6)$ & 0.022 \\
\hline Red blood cells $\left(10^{6} / \mathrm{mm}^{3}\right)$ & $4.5(0.4)$ & $4.9(0.4)$ & 0.017 \\
\hline Glycemia (mg/dl) & $81(14)$ & $92(11)$ & 0.026 \\
\hline $\mathrm{HbA1c}(\%)$ & $5.3(0.4)$ & $5.2(0.4)$ & 0.941 \\
\hline Sodium (mEq/l) & $142(2)$ & $142(0.2)$ & 0.755 \\
\hline Potassium (mEq/l) & $4.2(0.3)$ & $4.1(0.2)$ & 0.442 \\
\hline Chloride $(\mathrm{mEg} / \mathrm{l})$ & $104(3)$ & $104(2)$ & 0.522 \\
\hline Bicarbonate $(\mathrm{mEq} / \mathrm{l})$ & $28(2)$ & $29(1)$ & 0.140 \\
\hline
\end{tabular}

*All vaues are means (S.D.) unless otherwise stated. Differences among the matched groups were evaluated by the paired Student's $t$-test for normally distributed variables and Wilcoxon signed ranks test for other variables.

\section{GFR: patients with Cushing's disease versus controls}

Primary endpoints for GFR are summarized in Table 3. A one-way, between-groups MANOVA showed that there was a statistically significant difference between patients with Cushing's disease (cases) and healthy controls for the combined dependent variables (Wilks' lambda $\left.=0.607 ; F_{5,30}=3.89, P=0.008\right)$. The value obtained for partial eta squared is 0.393. Partial eta squared indicates the magnitude of the differences between means. Partial eta squared, also known as the MANOVA effect size statistic or the 'strength of association', represents the proportion of the variance in the dependent variable (i.e. the five outcome measures of GFR, considered as a cluster) that can be explained by the independent variable (Cushing's disease). To interpret the strength of eta squared values the following guidelines from Cohen (17) can be used: $0.01=$ small effect; $0.06=$ moderate effect; $0.14=$ large effect (17). The value of 0.393, is thus considered quite a large effect. This means that in our pilot study $39.3 \%$ of the variance in GFR can be explained by the presence of Cushing's disease. When the results for the dependent variables were considered separately, and using a Bonferroni adjusted alpha level of 0.010 ( $=0.05$ divided by 5$)$, the following differences reached statistical significance: GFR calculated from 24-h creatinine clearance, 24 -h creatinine clearance normalized for a body surface of $1.73 \mathrm{~m}^{2}$ and GFR estimated by the $\mathrm{MDRD}_{2}$ formula. No statistical difference could be demonstrated for the GFR as estimated by the Cockroft-Gault formula.

As most patients had been cured of Cushing's disease, we were interested to know whether analyzing only this subgroup would still give the same results. In this regard, a MANOVA analysis performed in the subgroup of 15 patients cured of Cushing's disease upon entry in the current study yielded results essentially identical to those for the full group (data not shown). 
Table 3 GFR among 18 patients with Cushing's disease and 18 healthy controls.*

\begin{tabular}{lcrr}
\hline $\begin{array}{l}\text { Method used to estimate glomerular filtration rate } \\
\text { (dependent variable) }\end{array}$ & $\begin{array}{c}\text { Cushing's disease } \\
\text { (cases) }\end{array}$ & $\begin{array}{c}\text { Healthy individuals } \\
\text { (controls) }\end{array}$ & $\boldsymbol{P}$ value \\
\hline 24-h creatinine clearance $(\mathrm{ml} / \mathrm{min})$ & $82(20)$ & $99(17)$ & 0.005 \\
24-h creatinine clearance $1.73 \mathrm{~m}^{2}\left(\mathrm{ml} / \mathrm{min}\right.$ per $\left.1.73 \mathrm{~m}^{2}\right)$ & $79(18)$ & $95(16)$ & 0.006 \\
Cockroft-Gault $(\mathrm{ml} / \mathrm{min})$ & $88(33)$ & $101(27)$ & 0.108 \\
Cockroft-Gault per $1.73 \mathrm{~m}^{2}\left(\mathrm{ml} / \mathrm{min}\right.$ per $\left.1.73 \mathrm{~m}^{2}\right)$ & $85(23)$ & $95(21)$ & 0.155 \\
MDRD $_{2}\left(\mathrm{ml} / \mathrm{min}\right.$ per $\left.1.73 \mathrm{~m}^{2}\right)$ & $75(16)$ & $88(15)$ & 0.008 \\
\hline
\end{tabular}

Significance of the overall MANOVA model: Wilks' lambda $=0.607, F_{5,30}=3.89, P=0.008$. Importance of the impact of Cushing's disease on GFR: partial eta squared value for the overall MANOVA model $=0.393$.

When the results for each dependent variable estimating GFR are then considered separately, a Bonferroni adjusted alpha level of 0.010 ( 0.05 divided by 5) might be used, and readers are advised to consider only smaller $P$ values as potentially important. * All values are means (S.D.), unless otherwise stated.

Glomerular filtration was also evaluated in the following subgroups of patients with Cushing's disease: diabetes versus no diabetes and hypertension versus no hypertension at the time of diagnosis; and, upon entry in the current study, cured versus active disease and hydrocortisone treatment versus no corticosteroid substitution. We could not demonstrate any statistical difference between these subgroups with regard to GFR (data not shown).

Although our study was not designed to investigate changes of GFR over time, we were able to take advantage of the data from six patients with Cushing's disease whose GFR was calculated at the time of diagnosis. During a mean $( \pm$ S.D. $)$ follow-up period of $11.3 \pm 6.9$ years the mean $( \pm$ S.D.) 24 -h creatinine clearance dropped from $107 \pm 20 \mathrm{ml} / \mathrm{min}$ at initial diagnosis of Cushing's disease to $84 \pm 22 \mathrm{ml} / \mathrm{min}$ upon entry in the current case-control study. With the numbers available, this slight decline in 24-h creatinine clearance of $-2.3 \mathrm{ml} / \mathrm{min}$ per year among patients diagnosed with Cushing's disease is not statistically significant (paired $t$-test: $P=0.08$, degrees of freedom $=5$ ).

Among the patients with Cushing's disease we identified four patients $(22 \%)$ with chronic kidney disease, i.e. GFR $<60 \mathrm{ml} / \mathrm{min}$ per $1.73 \mathrm{~m}^{2}(18)$. Table 4 lists the complete description of the characteristics of these four patients, including the risk factors for cardiovascular disease and the GFR estimates. As a result of these GFR estimates, the following investigations were performed: albumin-creatinine ratio in a random untimed urine specimen, examination of the urine sediment for erythrocytes and leukocytes, and imaging of the kidneys by ultrasonography. One patient (VF, Table 4) had bilateral millimetric nephrolithiasis with negative urine sediment and albuminuria. His calcium-phosphor metabolism was normal. Two patients (VM and WJ, Table 4) had bilateral nephrangiosclerosis as shown on echographic evaluation (small kidneys and decreased cortex size). Both patients were treated for cardiovascular risk factors and ACE inhibition. One patient (BM, Table 4) had normal urine sediment and ultrasonography.

\section{Predictors of GFR among patients with Cushing's disease}

Multiple regression analysis showed that the duration of the active disease was the best predictor for glomerular filtration, as measured or calculated by any of the different methods (Table 5). Total cholesterolemia was a significant predictor for 24-h creatinine clearance (Table 5, models 1 and 2). Waist size was a significant predictor for glomerular filtration, as estimated by both the 24-h creatinine clearance and the Cockcroft-Gault formula (Table 5, models 1 and model 3 respectively).

Similar multiple regression analyses performed in the subgroup of 15 patients cured from Cushing's disease upon entry to the current study yielded results essentially identical to those for the full group (data not shown).

\section{Discussion}

To our knowledge, our pilot study is the first to report a slight but statistically significant decrease in GFR among patients with Cushing's disease. In addition, we found that disease duration is the strongest predictor for GFR.

The sample of patients we included was representative of the general Cushing's disease population. When comparing clinical features at diagnosis with the data described in the literature, we observed similar clinical signs, although some more specific symptoms i.e. thin skin with easy bruising and osteoporosis were less prevalent $(19,20)$. This discrepancy may be explained by the retrospective nature of our study. Also, both of the other studies were conducted in the early 1980s, when the clinical picture of Cushing's disease was usually more pronounced at the time of diagnosis.

Comparing current laboratory values, patients with Cushing's disease had a lower calciuria, hematocrit and number of red blood cells. These unexpected findings have no clear-cut explanation. The lower blood glucose in cases compared with controls might be 
Table 4 Characteristics of the 4 patients with Cusing's disease having chronic kidney disease stage $3\left(\mathrm{GFR}<60 \mathrm{ml} / \mathrm{min} \mathrm{per} 1.73 \mathrm{~m}^{2}\right)(18)$.

\begin{tabular}{|c|c|c|c|c|}
\hline & Patient VM & Patient VF & Patient BM & Patient WJ \\
\hline \multicolumn{5}{|l|}{ Characteristics upon inclusion in the current study } \\
\hline Gender & Man & Man & Woman & Man \\
\hline Age at diagnosis of Cusing's disease (years) & 53 & 35 & 38 & 62 \\
\hline Age upon inclusion in current study (years) & 67 & 56 & 45 & 74 \\
\hline Duration of the active disease (years) & 13 & 20 & 3 & 16 \\
\hline Current status of Cushing's disease (curred or active) & Still active & Still active & Cured & Cured \\
\hline Diabetes mellitus and/or impaired glucose tolerance & No & No & No & No \\
\hline BMI $\left(\mathrm{kg} / \mathrm{m}^{2}\right)$ & 29.8 & 25.6 & 27.6 & 20.9 \\
\hline Waist (cm) & 115 & 92 & 95 & 74 \\
\hline Systolic blood pressure (mmHg) & 135 & 140 & 120 & 120 \\
\hline Diastolic blood pressure (mmHg) & 74 & 80 & 70 & 80 \\
\hline Total cholesterolemia (mg/dl) & 248 & 174 & 253 & 304 \\
\hline HDL-cholesterolemia (mg/dl) & 65 & 75 & 67 & 102 \\
\hline LDL-cholesterolemia (mg/dl) & 147 & 84 & 137 & 180 \\
\hline Hemoglobin (g/dl) & 13.8 & 14.2 & 15.7 & 12.1 \\
\hline Hematocrit $(\%)$ & 41.1 & 42.2 & 47.3 & 36.9 \\
\hline Glycemia (mg/dl) & 107 & 89 & 82 & 84 \\
\hline $\mathrm{HbA} 1 \mathrm{c}(\%)$ & 5.8 & 5.2 & 5.2 & 5.3 \\
\hline Plasma creatinine (mg/dl) & 1.45 & 1.35 & 1.06 & 1.10 \\
\hline Plasma urea (mg/dl) & 63 & 67 & 31 & 44 \\
\hline Presence of microalbuminuria ( $>30 \mathrm{mg} / 24 \mathrm{~h})$ & No & No & No & No \\
\hline \multicolumn{5}{|l|}{ GFR } \\
\hline $24-\mathrm{h}$ creatinine clearance $(\mathrm{ml} / \mathrm{min})$ & 58.3 & 62.0 & 54.0 & 48.1 \\
\hline 24-h creatinine clearance per $1.73 \mathrm{~m}^{2}\left(\mathrm{ml} / \mathrm{min}\right.$ per $\left.1.73 \mathrm{~m}^{2}\right)$ & 49.9 & 57.4 & 54.3 & 52.3 \\
\hline Cockroft-Gault (ml/min) & 61 & 65 & 73 & 47 \\
\hline Cockroft-Gault per $1.73 \mathrm{~m}^{2}\left(\mathrm{ml} / \mathrm{min}\right.$ per $\left.1.73 \mathrm{~m}^{2}\right)$ & 52.2 & 59.9 & 73.1 & 51.1 \\
\hline $\mathrm{MDRF}_{2}\left(\mathrm{ml} / \mathrm{min}\right.$ per $\left.1.73 \mathrm{~m}^{2}\right)$ & 52 & 58 & 60 & 70 \\
\hline Yearly decline in $24-\mathrm{h}$ creatinine clearance $(\mathrm{ml} / \mathrm{min}$ per year) & NA & -2.52 & -6.43 & NA \\
\hline
\end{tabular}

related to hypoadrenalism in this group. Increased levels of insulin were not observed. This is probably related to the fact that BMI and waist were not significantly different compared with the controls. Cholesterol levels were not different when Cushing's disease patients and controls were compared. This is probably a drug effect, as most patients suffering from dyslipidemia were on statin therapy.

We observed no increased prevalence of micro-albuminuria among patients with Cushing's disease. The reason for the low prevalence of micro-albuminuria in the presence of low GFR in patients with Cushing's disease could indicate that the mechanisms responsible for micro-albuminuria are reversible after normalization of cortisol levels. In line with our findings, Koh et al. (8) studied 13 patients with Cushing's disease of whom 4 had a pituitary adenoma and 9 an adenoma or carcinoma of the adrenal gland: $80 \%$ of the patients with active disease suffered from albuminuria, but this phenomenon was almost completely reversed after normalization of endogenous hypercortisolemia.

Our finding, that patients with a history of Cushing's disease have a significantly lower GFR measured by creatinine clearance and the $\mathrm{MDRD}_{2}$ formula, is in accordance with the limited data published so far. In two previous studies Faggiano et al. $(9,10)$ determined the creatinine clearance using a 24-h urine collection. In both studies they reported that patients with Cushing's disease (active and cured) showed a lower clearance than controls, but the difference was not statistically significant. When we compare our study results with those of Faggiano et al. (9, 10) we notice that their control group did not include overweight individuals. When GFR was estimated by the Cockroft-Gault equation we found no statistical differences between our cases and controls. We also found that our Cockroft-Gault estimates for GFR had quite large standard deviations. A large standard deviation results from data with substantial variability, and so the ability to detect differences between groups becomes less obvious. Poor statistical power is further indicated if sample size is small and if only one outcome of primary interest (GFR estimated according to the Cockroft-Gault equation) is considered separately for statistical testing. Moreover, the Cockroft-Gault equation takes into account body weight, another potential source of random measurement error. These findings are in line with the current concept that the $\mathrm{MDRD}_{2}$ equation is more accurate and precise than the Cockroft-Gault equation for individuals with a GFR of less than $90 \mathrm{ml} / \mathrm{min}$ per $1.73 \mathrm{~m}^{2}(16,18)$. 
Table 5 Multiple regression analyses of potential predictors of GFR among patients with Cushing's disease.*

\begin{tabular}{|c|c|c|}
\hline Models with potential predictors for the GFR & Regression coefficient (S.E.) & $P$ value of regression coefficient \\
\hline $\begin{array}{l}\text { Model } 1 \\
\text { Disease duration (years) } \\
\text { Waist }(\mathrm{cm}) \\
\text { Cholesterolemia }(\mathrm{mg} / \mathrm{dl}) \\
\text { Predictors for the GFR measured by the } 24 \text {-h cre } \\
\text { Adjusted } R \text { squared }=58 \%, F_{3,13}=8.431 \text {, overa }\end{array}$ & $\begin{array}{lr} & -1.55(0.58) \\
& 0.41(0.18) \\
& -0.23(0.09) \\
\text { earance } & \\
\text { value }=0.002\end{array}$ & $\begin{array}{l}0.020 \\
0.038 \\
0.020\end{array}$ \\
\hline $\begin{array}{l}\text { Model } 2 \\
\text { Disease duration (years) } \\
\text { Waist }(\mathrm{cm}) \\
\text { Cholesterolemia }(\mathrm{mg} / \mathrm{dl}) \\
\text { Predictors for the GFR measured by the } 24 \text {-h cre } \\
\quad \text { clearance normalized for a body surface of } 1.7 \\
\text { Adjusted } R \text { squared }=59 \%, F_{3,13}=8.619 \text {, overa }\end{array}$ & $\begin{aligned} & -1.84(0.51) \\
& 0.08(0.15) \\
& 0.19(0.08) \\
& \\
\text { value }= & 0.002\end{aligned}$ & $\begin{array}{l}0.003 \\
0.614 \\
0.027\end{array}$ \\
\hline $\begin{array}{l}\text { Model } 3 \\
\text { Disease duration (years) } \\
\text { Waist }(\mathrm{cm}) \\
\text { Cholesterolemia }(\mathrm{mg} / \mathrm{dl}) \\
\text { Predictors for the GFR estimated by the Cockcro } \\
\text { Adjusted } R \text { squared }=59 \%, F_{3,13}=8.652 \text {, overa }\end{array}$ & $\begin{array}{l}\quad \begin{array}{r}-2.64(0.98) \\
1.24(0.30) \\
-0.03(0.15)\end{array} \\
\text { equation } \\
\text { value }=0.002\end{array}$ & $\begin{array}{l}0.018 \\
0.001 \\
0.829\end{array}$ \\
\hline $\begin{array}{l}\text { Model } 4 \\
\text { Disease duration (years) } \\
\text { Waist }(\mathrm{cm}) \\
\text { Cholesterolemia (mg/dl) } \\
\text { Predictors for the GFR estimated by the Cockcro } \\
\quad \text { and normalized for a body surface of } 1.73 \mathrm{~m}^{2} \\
\text { Adjusted } R \text { squared }=47 \%, F_{3,13}=5.625 \text {, overa }\end{array}$ & $\begin{array}{l}-2.45(0.76) \\
0.48(0.23) \\
-0.06(0.12) \\
\text { equation } \\
\text { value }=0.011\end{array}$ & $\begin{array}{l}0.007 \\
0.058 \\
0.611\end{array}$ \\
\hline $\begin{array}{l}\text { Model } 5 \\
\text { Disease duration (years) } \\
\text { Waist }(\mathrm{cm}) \\
\text { Cholesterolemia }(\mathrm{mg} / \mathrm{dl}) \\
\text { Predictors for the GFR estimated by the } \mathrm{MDRD}_{2} \\
\text { Adjusted } R \text { squared }=11 \%, F_{3,13}=1.668 \text {, overa }\end{array}$ & $\begin{aligned} & -1.49(0.70) \\
& -0.05(0.21) \\
& -0.00(0.15) \\
\text { value }= & 0.223\end{aligned}$ & $\begin{array}{l}0.052 \\
0.817 \\
0.977\end{array}$ \\
\hline
\end{tabular}

* For each model, the significance of the overall model is assessed by the $F$ statistic and its corresponding $P$ value. To assess whether the individual predictor (independent) variables from each multiple regression model are statistically associated with the outcome of interest, the readers become able, if they so desire, to do a Bonferroni (or other) adjustment for the multiplicity. We suggest considering a level of $P<0.0167$ as significant for these numerous comparisons, representing a Bonferroni correction of 0.05 divided by three predictor variables.

Using multiple regression analyses, the GFR (estimated by the different methods) was consistently influenced by the duration of the active disease. Overall, our analyses point to a deleterious effect of hypercortisolemia on GFR, with a persistently decreased GFR, even after cure of Cushing's disease. From a physiopathological point of view these findings are sound (21-29). Although acute corticosteroid administration in normal men does not modify creatinine clearance, these data do not reflect hemodynamic changes of chronic endogenous hypercortisolism that can influence (deteriorate) GFR (30). Indeed, chronic hypercortisolism influences vascular tone and may permanently alter vessel remodeling.

Arterial hypertension was not identified as a factor predictive of GFR in the current study. Hypercholesterolemia and abdominal adiposity, on the other hand, were identified as independent predictors, but their impact varied according to the method used to evaluate GFR. When plotting the relationship between weight and GFR, it has recently been shown that the
Cockroft-Gault and $\mathrm{MDRD}_{2}$ estimates display a different and opposite pattern. For a greater weight, Cockroft-Gault estimates were higher; whereas $\mathrm{MDRD}_{2}$ estimates were lower. Since both groups, patients with Cushing's disease and controls, had a similar BMI these findings cannot account for the differences in GFR between our study groups. They can however explain the different impact of waist measurement (correlated to $\mathrm{BMI}$ ) on estimated creatinine clearance: the higher the waist measurement the higher the Cockroft-Gault estimates, the higher the waist measurement the lower the $\mathrm{MDRD}_{2}$ estimates (31). Treatment of cardiovascular risk factors may have confounded these observations further. Most patients were followed closely in a tertiary referral setting by endocrinologists aware of the treatment of these risk factors. Five out of 18 patients were treated for arterial hypertension, and 5 out of 18 received an antilipemic drug. Even then, hypercholesterolemia was a strong and independent predictor of creatinine clearance. In line with these findings, it has recently been demonstrated that the 
interpretation of the relationship between cardiovascular risk factors and kidney function is affected by the method used to estimate kidney function. Indirect measures (Cockroft-Gault, $\mathrm{MDRD}_{2}$ ) should therefore be used with caution (31). Finally, visceral adiposity is common in patients with Cushing's disease, mainly because glucocorticoids induce fat accumulation in the visceral area. Colao et al. (4) demonstrated that this feature is not completely reversible in patients with Cushing's disease. The decrease of GFR in people with a history of Cushing's disease might be a consequence of the metabolic syndrome that has been shown to affect these people $(32,33)$.

The strengths of our study include feasibility (related to study design), the inclusion of an adequate control group, the precision and accuracy of the creatinine measurement used in our calculations and the power of the statistical methodology.

A prospective cohort study on kidney failure among patients with Cushing's disease might not be feasible taking into account the low prevalence of Cushing's disease, and the rare occurrence of the main outcome of interest (i.e. progression to kidney failure). Moreover, a prospective outcome comparison between patients with Cushing's disease and control patients would require a very long follow-up period. Another possible study design is the prospective evaluation of patients treated with corticosteroids. In these patients, however, different factors related to the underlying (and treated) disease may confound the outcome measure (i.e. GFR).

We balanced both groups prognostically by taking into account age and gender, which have been shown to be strong and independent predictors for kidney function.

It is well recognized that creatinine measurements from different laboratories using the same samples may differ systematically by as much as $0.23 \mathrm{mg} / \mathrm{dl}$. The $z$-scores for accuracy provided no evidence for a statistically significant over- or underestimation of plasma creatinine measurements compared with the external reference standard of the Federal Government. Consecutive evaluations of precision and accuracy during the study period (March-December 2003) did not show any significant trend.

MANOVA performs only a single test to assess whether several outcome (dependent) variables (as a cluster) are associated with the exposure (independent) variables without worrying about adjusting for multiple comparisons. Likewise, multiple regression analyses investigate the independent effect of several prognostic factors (explanatory variables) on one outcome measure (dependent variable), also without worrying about adjusting for multiple comparisons. Both statistical methods allow for the quantification of the importance of the impact of the independent variable(s) on the dependent variable(s) by using an effect size statistic (partial eta squared and adjusted $R$ squared, for
MANOVA and multiple regression analysis respectively).

We did not assess the glomerular function of our participants by the gold standard methodology, i.e. by using the exogenous filtration marker inulin or any other validated filtration marker including, for example, iohexolon or iodine-125-iothalamate. In addition, we did not attempt to assess renal blood flow, renal vascular resistance or filtration fraction. Instead, in our pilot study, we have focused on GFR and used non-invasive methods. In the current study the magnitude of the impact of Cushing's disease on GFR was evaluated by partial eta squared, the effect size statistic of the MANOVA model. The value in our study is 0.393 , which, according to generally accepted criteria (17), is considered quite a large effect. This means that in our study $39.3 \%$ of the variance in GFR is explained by the presence of Cushing's disease. Advantages for the use of creatinine as a filtration marker are that it is easy to measure, inexpensive and widely available. Irrespective of GFR, however, there are a number of factors affecting serum creatinine levels: increased muscle mass (increased creatinine levels), age, female gender, muscle wasting (muscle mass is lowered in patients with Cushing's disease), a vegetarian diet and malnutrition (decreased creatinine levels). Although inter-group comparison may be valid, the Cockroft-Gault and $\mathrm{MDRD}_{2}$ formulae were not designed or validated to estimate near-normal GFRs. The Cockroft-Gault formula was derived in 249 hospitalized white men, and the $\mathrm{MDRD}_{2}$ formula in 1628 participants with chronic kidney disease (GFR, $40 \mathrm{ml} / \mathrm{min}$ per $1.73 \mathrm{~m}^{2}$ or less) who were predominantly white. Both formulae have not been validated in: individuals at the extremes of body size, with high levels of dietary meat intake, overweight or obesity; individuals at increased risk of chronic kidney disease; conditions associated with muscle wasting (e.g. patients with Cushing's disease); normal individuals (e.g. population-based healthy controls). These equations may be less accurate in individuals who were not included in the study population from which the equation was developed or validated. According to current guidelines, however, the most appropriate estimate of GFR in these special circumstances is a measurement of creatinine clearance, obtained from a 24-h urine collection to measure creatinine excretion rate and a single measurement of plasma creatinine concentration $(34,35)$.

As we did not use a prospective cohort design for the current investigation, the decline of GFR over time could not be studied appropriately. In a prospective cohort study, changes of GFR over time could help to individualize a subgroup of patients particularly at risk for a rapidly progressive decline in GFR.

Our study was also limited by the small number of patients and the fact that most patients were cured upon enrolment in the current case-control study. In 
particular, we could not perform a separate evaluation of the different risk factors in the active stage of the disease. This is of importance in unraveling the mechanisms underlying kidney damage. Even with the small number of patients available, and within the limits of study design and study methodology, we were able to demonstrate statistically significant effects suggesting that Cushing's disease may contribute, directly or indirectly, to a reduction in GFR.

Keeping these limitations in mind, our findings might have important clinical implications. Four of our patients with Cushing's disease (22\%) showed a GFR below $60 \mathrm{ml} / \mathrm{min}$ per $1.73 \mathrm{~m}^{2}$ at the time of examination. According to the National Kidney Foundation guidelines (18), these patients should be re-examined (i.e. to confirm that GFR is still $<60 \mathrm{ml} / \mathrm{min}$ per $1.73 \mathrm{~m}^{2}$ ) and have additional evaluation by analysis of blood and urine and by imaging studies of the kidneys. They should be treated for their comorbid conditions and evaluated and treated for complications. Patients with an estimated GFR between 60 and $89 \mathrm{ml} / \mathrm{min}$ per $1.73 \mathrm{~m}^{2}$, with additional cardiovascular risk factors should be further evaluated for markers of renal damage; this means proteinuria, other abnormalities in urine sedimentation tests and detection of renal pathology using imaging tests. Measures need to be taken to slow the progression of renal disease, and there is a clear need for risk evaluation and interventions related to cardiovascular risk factors and treatment of concomitant factors.

In conclusion, to our knowledge our pilot study is the first to report a decreased GFR in patients with Cushing's disease. In addition, we found that disease duration is the strongest predictor for GFR. Consequently, an aggressive initial treatment of patients with Cushing's disease should be considered. Our findings should also be taken into account when designing follow-up strategies for patients with Cushing's disease. Close follow-up of patients with Cushing's disease (even if they are cured), early detection and strict control of cardiovascular risk factors and monitoring of GFR at regular intervals seems mandatory for patients with Cushing's disease. Furthermore, for certain drugs, the dosage should be adapted to the individuals GFR.

\section{Acknowledgements}

This work was supported by grants of the Willy Gepts foundation, Academisch Ziekenhuis van de Vrije Universiteit Brussel (AZ-VUB).

The authors thank P. Couck MD, Laboratorium Klinische Chemie, Academisch Ziekenhuis van de Vrije Universiteit Brussel (AZ-VUB), for providing the characteristics of the creatinine assay.

\section{References}

1 Greenblatt SH. Harvey Cushing's paradigmatic contribution to neurosurgery and the evolution of his thought on his specialisation. Bulletin of the History of Medicine 200377 789-822.

2 Trainer PJ \& Grossman A. The diagnosis and differential diagnosis of Cushing's syndrome. Clinical Endocrinology (Oxford) 1991 34 317-330.

3 Newell-Price J, Trainer P, Besser M \& Grossman A. The diagnosis and differential diagnosis of Cushing's syndrome and PseudoCushing's states. Endocrine Reviews 199819 647-672.

4 Colao A, Pivonello R, Spiezia S, Faggiano A, Ferrone D, Filippella M, Marzullo P, Cerbone G, Sicilliani M \& Lombardi G. Persistance of increased cardiovascular risk in patients with Cushing's disease after five years of successful cure.Journal of Clinical Endocrinology and Metabolism $1999 \mathbf{8 4}$ 2664-2672.

5 Leoncini G, Viazzi F, Parodi D, Vettoretti S \& Ratto E. Mild renal dysfunction and subclinical cardiovascular damage in primary hypertension. Hypertension 200342 14-18.

6 Chen J, Muntner P, Hamm L, Jones DW, Batuman V, Fonseca V, Whelton PK \& Jiang $\mathrm{H}$. The metabolic syndrome and chronic kidney disease in U.S. adults. Annals of Internal Medicine 2004 140 167-174.

7 Hatton J, Parr M \& Blouin RA. Estimation of creatinine clearance in patients with Cushing's syndrome. DICP 198923 974-977.

8 Koh J-M, Kim JY, Park JY, Shong YK, Hong SK, Kim GS \& Lee KU. Increased urinary albumin excretion in Cushing's syndrome: remission after correction of hypercotisolemia. Clinical Endocrinology $2000 \mathbf{5 2} 349-353$.

9 Faggiano A, Pivonello R, Melis D, Alfieri R, Filippella M, Spagnulo G, Salvatore F, Lombardi G \& Colao A. Evaluation of circulating levels and renal clearance of natural amino acids in patients with Cushing's disease. Journal of Endocrinological Investigation $200225142-151$.

10 Faggiano A, Pivonello R, Filippella M, Di Somma C, Petretta M, Lombardi G \& Colao A. Nefrolithiasis in Cushing's disease: prevalence, ethiopathogenesis and modification after disease cure. Journal of Clinical Endocrinology and Metabolism $2003 \mathbf{8 8}$ 2076-2080.

11 Arnaldi G \& Angeli A. Diagnosis and complications of Cushing's syndrome: a consensus statement. Journal of Clinical Endocrinology and Metabolism $2003 \mathbf{8 8} 5593-5602$.

12 Anon. Clinical Guidelines on the Identification, Evaluation and Treatment of Overweight and Obesity in Adults: the Evidence Report, pp 98-4083, NIH publication. Bethesda, MD: National Institutes of Health, 1998.

13 Anon, World Health Organisation-International Society of Hypertension guidelines for the management of hypertension. Guidelines Subcommittee. Journal of Hypertension 199917 151-183.

14 Larn TK \& Leung DR. More on simplified calculation of body surface area. New England Journal of Medicine 3181130.

15 Cockcroft DW \& Gault MH. Prediction of creatinine clearance from serum creatinine. Nephron 197616 31-41.

16 Levey AS \& Bosch JP. A more accurate method to estimate glomerular filtration rate from serum creatinine: a new prediction equation: Modification of Diet in Renal Disease Study Group. Annals of Internal Medicine 1999130 461-470.

17 Cohen J. Statistical Power Analysis for the Behavioral Sciences. Hillsdale, NJ: Erlbaum, 1988.

18 Levey AS, Coresh J, Balk E, Kausz AT, Levin A, Steffes M, Hogg R, Perrone R, Lau J \& Eknoyan G. National kidney foundation practice guidelines for chronic kidney disease: evaluation, classification, and stratification. Annals of Internal Medicine $2003139137-147$.

19 Urbanic RC \& George JM. Cushing's disease: 18 years of experience. Medicine 198160 14-26.

20 Ross EJ \& Linch DC. Cushing's syndrome - killing disease: discriminatory value of signs and symptoms aiding early diagnosis. Lancet $19822646-649$. 
21 Pirpiris M, Sudhir K \& Yeung S. Pressor responsiveness in corticosteroid induced hypertension in humans. Hypertension 1992 $19571-574$

22 Brem AS. Insights into glucocorticoid associated hypertension. American Journal of Kidney Diseases 200137 1-10.

23 Brem AS, Bina RB, Mehta S \& Marshall J. Glucocorticoids inhibit the expression of calcium-dependent potassium channels in vascular smooth muscle. Molecular Genetics and Metabolism 1999 $67573-577$.

24 Whitworth JA, Schyvens CG, Zhang Y, Andrews MC, Mangos GJ \& Kelly JJ. The nitric oxide system in glucocorticoid-induced hypertension. Journal of Hypertension 200220 1035-1043.

25 Wallerath I, Witte K, Schafer SC, Schwartz PM, Prellwitz W, Kleinert H, Lehr HA, Lemmer B \& Fortstermann U. Down-regulation of the expression of endothelial NO synthetase is likely to contribute to glucocorticoid-mediated hypertension. PNAS $1999 \mathbf{9 6}$ 1357-1362.

26 Kelly JJ, Williamson P, Martin A \& Whitworth JA. Effects of oral Larginine on plasma nitrate and blood pressure in cortisol-treated humans. Journal of Hypertension 200119 263-268.

27 Mangos GJ, Walker BR, Kelly JJ, Lawson JA, Webb DJ \& Whitworth JA. Cortisol inhibits cholinergic vasodilatation in the human forearm. American Journal of Hypertension $2000 \mathbf{1 3}$ 1155-1160.

28 Iuchi T, Akaike M, Mitsui T \& Ohshima Y. Glucocorticoid excess induces superoxide production in vascular endothelial cells and elicits vascular endothelial dysfunction. Circulation Research $20039281-87$.

29 Sala C, Ambriosi B \& Morganti A. Blunted vascular and renal effects of exogenous atrial natriuretic peptide in patients with
Cushing's disease. Journal of Clinical Endocrinology and Metabolism 200186 1957-1961.

30 Connell JM, Whitworth JA, Davies DL, Lever AF, Richards AM \& Fraser R. Effects of ACTH and cortisol administration on blood pressure, electrolyte metabolism, atrial natriuretic peptide and renal function in normal man. Journal of Hypertension $1987 \mathbf{5}$ 425-433.

31 Verhave JC, Gansevoort RT, Hillege HL, de Zeeuw D, Curhan GC \& de Jong PE. (for the PREVEND Study Group). Drawbacks of the use of indirect estimations of renal function to evaluate the effect of risk factors on renal function. Journal of the American Society of Nephrology 200415 1316-1322.

32 Hayashi Y, Morikawa A \& Makino M. Heterogenicity of urinary albumin from diabetic patients. Clinica Chimica Acta 1990190 93- 103 .

33 Babazono T, Kapor-Drezgic J \& Whiteside C. Altered expression and subcellular localisation of diacylglycerol-sensitive protein kinase isoforms in diabetic rat glomerular cells. Diabetes 1998 $47668-676$.

34 Coresh J, Astor B, McQuillan G, Kusek J, Greene T, Van Lente \& Levey A. Calibration and random variation of the serum creatinine assay as critical elements of using equations to estimate glomerular filtration rate. American Journal of Kidney Diseases 2002 39 920-929.

35 Stevens L \& Levey A. Measurement of kidney function. Medical Clinics of North America $2005 \mathbf{8 9} 457-473$.

Received 3 June 2005

Accepted 2 September 2005 